\title{
Pobreza, neoliberalismo y cristianismo
}

\section{F. Javier Vitoria Cormenzana, Instituto Diocesano de Teología y Pastoral, Bilbao, Centro de Reflexión Teológica, San Salvador}

\section{Erradicar la pobreza y repartir equitativamente la riqueza}

La reciente celebración del Año Internacional para la Erradicación de la Pobreza (1996) no ha sido nada cficiente a la hora de aproximarse al objctivo que su propio enunciado evocaba. Sin embargo, ha dejado tras de sí un inquietante desafío: ise convertirá el siglo XXI en el Tiempo del reparto equitativo de la riqueza? No lo sabemos y he de confesar que a veces me temo lo peor. Las voces que diariamente claman más y más en este sentido, parecen hacerlo en el inmenso desierto de la apatia de la cultura dominante. Parodiando a Miguel Angel Asturias, me alrevería a decir que la globalización de nuestro mundo resulta inmensamente grande para la fatiga de los pobres y se va haciendo paulalinamente más pequeña para su congoja. Sin cmbargo, si tomáramos la pregunta como expresión de un anhelo humano, podremos asegurar, sin temor a equivocarnos, que nos encontraríamos con una aspiración compartida por la totalidad de los habitantes de "la aldea global". Incluidos los neoliberales. Más aún, podremos encontrar bastantes de ellos que dicen que lo son justamente para poder satisfacer ese deseo. Se necesitaría ser cruelmente inmisericorde para no sumarse a una aspiración humana lan noble. Pero semejante unanimidad no nos permite ser excesivamente optimistas en relación con las posibilidades de que nuestros nietos la vean satisfecha. La mayor parte de las veces los sentimicntos humanilarios hacia los pobres son tan buenos como ineficaces. Y la razón es muy sencilla: frecuentemente los sentimientos y los intereses individuales y sociales ni coinciden, ni se ponen de acuerdo en materia de solidaridad. Por eso sucede que muchas de las voces que se rasgan las vestiduras por la desatención pública a una cuestión clave para el futuro de la humanidad, como es la del desarrollo sostenible, manitiesten una notable falta de interés por los pobres de hoy. Me nicgo a crecr que la razón de este desajuste 
estribe en que algunos acarician secretamente la idea de que la solución a la pobreza es que se mueran los pobres, aunque haya podido leer en un periódico español semejante cínica propuesta: un burócrata del Banco Mundial parece haber afirmado en Nairobi que la solución de África estaba en las muertes por hambre y Sida, que en 10 años barrerian de miserables el continente africano ( $E l$ Pais, 20 de agosto de 1996).

Hay quienes estiman que este lipo de opiniones extremas son más frecuentes de lo que pensamos. Personalmente, prefiero tomar en consideración el creciente número de economistas, sociólogos y politólogos que comienzan a pensar que el nivel de desigualdad y pobreza es tal que el planeta puede llegar a su colapso total. En su opinión, la reducción del foso de la desigualdad y el alivio de la miseria de las mayorías empobrecidas ya conslituyen, juntamente con la cuestión ecológica, los problemas centrales en la próxima fase de revolución industrial. Poco a poco, la contundencia de los datos y la insistencia del pensamiento solidario van abriendo paso a la idea de que sólo hay un "nosotros" en la solución a la pobreza y de que buscarla, como si se tratara de un problema de "los otros", no es ni humanitaria, ni políticamenle correcio.

La erradicación de la pobreza y el reparto de la riqueza es el gran anhelo utópico que va a guiar mi reflexión sobre neoliberalismo y cristianismo. Articularé mi trabajo como explicación de una doble convicción que formularé en forma de tesis.

\section{EI neoliberalismo}

\section{El crecimiento de excedentes humanos en el interior del sistema mundo.}

El hecho sociocultural más relevante de este final de siglo es el crecimiento de excedentes humanos en el interior del sistema de globalización mundiall. El actual sistema de economía de mercado se construye sobre una lógica que

1. Todavía eslamos lejos de superar lo que ya sc conoce como "larga noche ncoliberal" de la década de los ochenta (la del reaganismo y el thatcherismo). A pesar de su fracaso (recesión económica, inestabilidad financiera, aumento alarmante del número de pobres, etc.), el neoliberalismo siguc siendo la ideología más influyente del mundo, no nos engañemos. La idcología ncoliberal de nucstra época es "darwinismo social, Ja doctrina que exalta la necesidad y conveniencia para el conjunto de la sociedad (y de la especie humana) de que algunos micmbros de clla, los mejor dotados y capacitados para la competencia cconómica, tengan todas las oportunidades para triunfar y sobrevivir en el enlirentamiento de los hombres con la naluraleza y de los hombres entrc sí para mantener el control sobre los recursos creadores de riqueza", L. de Scbastiản, "La gran contradicción del neo-liberalismo moderno. O la sustilución del humanismo liheral por el darwinismo social". Cristianisme $i$ Jusricia, Barcclona, 1989, p. 7; cfr. AA.VV. La larga noche neoliberal. Polficas economicas de los 80, Barcelona-Madrid, 1993. 
sostiene y desemboca en un mundo dual de ricos y pobres, en el que los deseos ilimitados y las demandas cada vez más cualitativas de una minoría (de ricos) lerminan por imponerse sobre las necesidades de supervivencia de la mayoría (de pobres). No es cuestión de volver a repelir datos ya suficientemente conocidos, ni de rememorar imágenes que hieren la sensibilidad de cualquier bien nacido. Retengamos simplemente un par de datos.

Según el informe del PNUD (1996), el Producto Interno Brulo del planeta lierra gira en torno a los 23 trillones de pesetas. Los paises desarrollados consumen 18 de ellos y sólo quedan 5 para el 80 por ciento restante de la población. Esta situación mundial de dependencia asimétrica se hace especialmente sangrante si consideramos que alcanza al comercio mundial de alimentos (más de las $2 / 3$ partes de las exporlaciones e importaciones mundiales de productos alimenticios corresponden a los países desarrollados), y explica la geografía del hambre: el hambre y la malnutrición de hoy en día no son el resultado de una escasez global de alimenlos, sino fruto (al menos, parcial) de las polílicas proteccionistas de aquellos países, que han contribuido a crear e incrementar la dependencia alimentaria de muchas zonas crónicamente pobres del tercer mundo hasta el extremo de que 800 millones de sus habitantes no puedan salisfacer su primera necesidad, alimentarse, y padecen desnutrición 2.

El reverso de la creciente globalización de las relaciones económicas y del avance imparable de la ciencia y la tecnología lo constituyen los millones de seres humanos que quedan tirados a un lado del camino, viendo pasar el tren de la prosperidad. Y con ellos muchas y variadas formas de vida (desde los pueblos indigenas y tribales con sus culturas ancestrales, las sociedades campesinas autosuficientes, el artesanado tradicional, las pequeñas empresas familiares, que en total suman miles de millones de seres humanos sobre todo en Africa, Asia y América Latina), se ven súbitamente destinadas a desaparecer con pocas perspectivas alternativas para su futuro3.

Esos enormes contingenles humanos viven atrapados en un círculo auténticamente diabólico, el de la desocupación y lu insolvencia, que los condena a la marginación social y a la exclusión: como no pueden comprar, no pueden "ser" gente reconocida como tal en la comunidad mundial4. La exclusión de la población, no sólo en la periferia del sistema mundo, se hace inevitable. Son los efectos del huracán de la globalización, que pasa desde hace

2. Cfr. B. Sulcliffe (coord.), El incendio frio. Hambre, alimentacion y desarrollo. Barcelona, 1996.

3. Cfr. R. Slavenhagen. "Li cducación encicra un tesoro: cl informe a la UNESCO", Piginas 146 (agosto 1997) pp. 18-20.

4. Cfr. Jung Mo Sung, "Deseo mimélico, exclusión y cristianismo", Pasos 69, 1977, p. 12. 
más de dos décadas por encima de América Latina, así conı pasa por encima del mundo entero 5 .

\section{El catecismo neoliberal}

Mientras todo crece, este panorama de inhumanidad, resultado de lo que F. Fernández Bucy denomina "la barbarie de los nuestros"6, no deja Je escucharse el conocido sonsonete del catecismo neoliberal, a saber: que resulta insensato y Irasnochado esperar ya cambios cualitalivos en el sislema mundial de mercado, y que ahora únicamente locil propiciar los ajustes y los encauzamientos que exija la mejoría en su funcionamiento, con tal de no interferir sistemáticamente en Él. Se ha decrelado "el lin de la hisloria" (F. Fukuyama).

En el coro conservador hay voces que reclaman el concurso de los valores morales con el fin de mitigar los efectos indeseables de una competitividad basada en el cxclusivo criterio del beneficio, y formalizar la evidencia de que no hay democracia ni libertad sin unos mínimos de cohesión social. Entre ellas se encuentra la del conocido banquero español y destacado miembro del Opus Dei, R. Termes. Según su opinión, el capitalismo dará lodos los frutos que cabe esperar de él, si en lugar de intentar corregir coactivamente su funcionamiento, impulsamos la mejora del sistema ćtico-cultural y del jurídico-insıitucional en los que el económico se encuadra, para adecuarlos a una antropología basada en la naturaleza y el vilor del hombre como ser racional y libre. El reto y el esfuerzo consiste en hacer real la yuxtaposición, dentro de la mulua independencia, del sistema económico liberal y de un sistema de valores anclado en normas permanentes y objetivas desde el punto de vista moral y racional7. Se trata de una posición muy semejante a la postulada por los neoconservadores norteamericanos.

Estamos ante una de las mentiras implantadas por la ideología y la praxis neoliberal. Esta posición ignora u oculta que la mulua independencia de los sistemas no es posible. Más aún, que el sistema económico ha colonizado el ético-cultural hasta el punto de que "cl monoteísmo del dincro" y el "milo del crecimiento económico" ha invadido lodos los ámbilos humanos (la vida privada, el trabajo, la vida polílica, elc.), aunque no sean capaces de otorgar la felicidad que prometen, ni siquiera a sus beneficiarios. El dinero se ha converlido en el motor de la historia, de una historia inhumana, por supuesto. Hace ticmpo que dejó de ser un instrumento de intercambio para convertirse en depositario de un valor que garantizaba la satisfacción de las necesidades futuras

5. Cfr. F. J. Hinkelammert, "El huracjin de la globalización: la exclusión y la Jestrucción Jel medio ambiente vislos desde la leoría de la dependencia", Pasos 69. 1007. pp. 21-27.

6. Cfr. La harbarice. De ellos y de los muesiros, Burceloni-Bucnos Aires-Mćxico, 1995.

7. Cfr. "Antropologia del capitalismo. Un debate abierto", Cambio 16. Barcelona, 1992. 
(la atención de una entermedad o de un siniestro imprevisible, la educación de los hijos, los cuidados de la ancianidad, etc.). Pero en nuestra cultura de la satisfacción funciona principalmente como depositario de sentido (otorga reconocimiento y salvación, es decir, existencia real y posibilidad de satisfacer los deseos todavía inimaginables del futuro) a quienes lo acumulan o pretenden hacerlo de modo ilimitado: los ricos y los poderes financieros.

No veo olra razón para que sus propietarios estén dispuestos a sacrificar por él todos los demás valores (a nivel privado, la salud personal, pero también la paz mundial8 y la dignidad y la vida de millones de empobrecidos de la Tierra9). Paradójicamente, solamente los pobres (p.e., esos 3,000 millones de personas que sobreviven en el mundo con menos de dos dólares diarios 10 ), que están privados del depósilo (el dinero), lo contemplan como deposilario de un valor, capaz de satisfacer sus muchas necesidades (comida, bebida, habitación digna, educación básica, etc.).

\section{La crueldad de la economia de mercado}

El enfoque de regeneración moral de la economía de mercado (jcuidado con no confundir economía de mercado con mercado!, pues no son sinónimos por mucho que se empeñe el neoliberalismo) resulta necesario para paliar algunos de los desmanes de "este orden necrófilo", pero totalmente insuficiente para corregir sus causas. La fisonomía de la economía de mercado tal como se practica al dia de hoy posee aquellos rasgos que suscitan el juicio absolutamente negativo de Juan Pablo II y no los que integran la hipótesis pontificia sobre el capitalismo "bueno"11.

8. Sólo en 1996 sc registraron veintiscis conflictos bélicos en el mundo.

9. Se calcula que al año mueren de hambre $\mathbf{3 6}$ millones de personas. En la cumbre de la FAO de 1996, 186 países acordaron reducir a la milad, antes del 2015, los 800 millones de personas que padecen hambre. Este tipo de decisiones, scgún los dirigentes políticos del mundo, se consideran polílicamente correctas, aunque no eviten la muerte por hambre de alrededor de 700 millones de personas en los próximos veinte años. Además, seguramente los informes mundiales de mañana certificarán el incumplimiento de los compromisos de hoy, de la misma manera que los actuales lo hacen con los compromisos de ayer, en relación con la dedicación del 0.7 por ciento del PIB a la coopcración. ¿Existirá en cl siglo XXI alguna instancia mundial capaz de exigir responsabilidades civiles y penales a los amos del mundo por sus incumplimientos o seguirán lirmando papeles con absoluta impunidad? ¡Qué razón tcría I. Ellacuría cuando pedía revertir la historia!

10 Según el informe del PNUD-1997, el 24 por ciento de la población de América Latina y el Caribe vive con menos de un dolar diario.

11 "Si por 'capitalismo' sc enticnde un sistema económico que reconoce el papcl fundamental y positivo de la empresa del mercado, de la propiedad privada y de la consiguiente responsabilidad para con los medios de producción, de la libre creatividad humana cn el sector de la cconomía, la repuesta es positiva... Pero si por 
El capilalismo triunfante, el realmente existente tras el colapso de socialismo, ya no necesita guardar las apariencias y mostrarse con rosiro humano. El marco instilucional y juridico de los estados y las organizaciones supraestales en lugar de ser instancia de garantía de la libertad integral de los ciudadanos del mundo, funciona como instancia de globalización. en orden a facilitar los flujos de mercancías y capilales y a fomentarlos por medio de subvenciones inmensas que ya superan las efecluadas por el Estado social 12.

Los mecanismos del mercado global —como ha recordado el magisterio pontificio- luncionan de modo casi automálico haciendo cada vez más rígidas cada una de esas siluaciones de pobreza y riqueza (SRS 16c). Su lógica interna favorece un modelo de desarrollo vicario en el que los ricos ejercen la función de representar a toda la humanidad en el disfrute de los bienes materiales de la creación 13, y en el que se considera normal que nazcan y muerall en la miseria millones de hombres y mujeres. Sus razonamientos ni se conmueven frente al hambre de las multitudes, ni expcrimentan el escándalo frentc al desamparo de la pirámide creciente de excedentes humanos del sistema. El sistema no liene corazón y “presupone una mística crucl del desempeño y del culto a la eficiencia"14.

Introducir un debate sobre capitalismo "bucno" versus capitalismo "malo" me parece estéril. Tampoco me referiré a la conocida (y burda) utilización de la simbología cristiana para legitimar el capitalismo deınocrático (M. Novak) o al intento de búsqueda de las raíces cristianas de la economia de libre mercado 15 , que de todo hay en la viña neoconservadora. Pero sí quiero manifestar que la lucha por la vida de los pobres y la contribución a la viabilidad histórica del reparto equitalivo de la riqueza del mundo (esta porfía sí me parece fecunda) pasa por la resistencia a la ideología neoliberal y que esta beligerancia comienza por la percepción clara y la comprensión rigurosa de su naluraleza.

'capilalismo' se entiende un sistema en el cual la liberlad en el ámbito económico, no cstá cncuadrada en un sólido contexto jurídico que la ponga al scrvicio de la libertad humana integral y la considere como una particular dimensión de la misma, cuyo centro es ético y religioso, cntonces la respuesta es absolutamente negativa" (Centesinus annus 42).

12. Cfr. F. J. Hinkelammer, op. cir., p. 23.

13. Cfr. L de Sebastián, "El neoliberalismo. Argumentos a favor y en contra". en Cristianisme i Justicia; Id. El neoliberalismo en cuestión, Barcelona-Santander, 1993, p. 28.

14. La frase es de Roberto Campos, exministro brasileño, y está cilada por Jung Mo Sung, op. cit., p. 11.

15. Cfr. A. A. Chaufen, Economía y ética. Raices cristianas de la economia de libre mercado, Madrid. 1991. 


\section{El neoconservadurismo como "religión"16}

En este sentido solamente quisiera alertar sobre una característica del neoliberalismo, el fundamentalismo o fanatismo económicol7 de su ideología del mercado, que ha dado lugar a que se pueda hablar de él como de una "religión"18. El proceso intenso de mesianización del mercado y la proclama de una evangelio triunfalista que descalifica cualquier olra alternaliva dislinta a la neoliberal 19 son dos de las manifestaciones del integrismo economicista, que reclama para sí fe en el valor absoluto de sus propuestas económicas y exige la aceplación ciega de lodas las reglas que extraen de su doctrina los que se pretenden los aulénticos depositarios de "esa revelación". "El admilir como verdades absolutas las proposiciones de los economistas es pasar de la economia -que es una disciplina científica entre otras- al economismo, que resulta un integrismo tan devastador como los integrismos religiosos"20.

Nada importa que, desde hace veinticinco años, todos los informes mundiales vengan denunciando el carácter mitológico de la "fe" neoliberal (a saber: que a mayor acumulación económica [crecimiento] corresponderá una mejor distribución de las riquezas y una mejoría en la vida de los pucblos pobres [desarrollo], y que a mayor eficiencia económica mejor legitimación del sistema), o que, más concretamente, se apunte que "el peligro hoy en día no proviene del pesimismo malthusiano (el temor a que el crecimiento de la producción alimentaria no vaya parejo al de la población), sino del optimismo malthusiano (la falsa creencia en que si solucionamos el problema de la producción de alimentos habremos resuelto el problema)"2l, los neoliberales seguirán erre que erre en sus trece, o sea, en su fie. Bajo pretextos de modernización y realismo, afirman el carácter inevitable de los procesos en curso, acusan de capitulación intelectual y expulsan a las tinieblas de lo irracional a lodos aquellos que se niegan a accplar que "el estado natural de la sociedad es el mercado"22.

16. Cfr. H. Assmann, "Las falacias religiosas del mercado", Cristianisme i Justícin. Burcelona, 1997.

17. Cfr. L. de Scbastián, Mundo rico, mundo pobre, Santander, 1992. p. 102.

18. Resulla ilustralivo de la importancia que comienza a tener esla característica el hecho de que esta consideración del neoliheralismo como "religion" no se hace exclusivamente desde los círculos de la tenlogia de la liberación latinoamericana. sino lambién desde el hemisferio norte del continenıc amcricano: cfr. M. Bcaudin. "Lc nco-liticralisme come 'religion'., Rulations, octubre 1095. pp. 238-240; "Solćriologic. cupitalisme el salul chrćlien". en J. C. Petit, J. C. Breton, Seul ou avec les aures ¿Le salut chrérion à l'cpreuve de la solidarité, Monireal, 1992. pp. 2.37. $28 \mathrm{I}$.

19. Cfr. II. Assmann, "Economia y Icologia", cn AA. VV, Conecpros fundamenrales del cristianismo, Madrid, 1993, p. 357.

20. Cfr. A. Jacquard, Yo acuso la economía triunfante, Barcelona, 19\%6. p. 86.

21. P. Strecten. "El hambre", en B. Sulcliffe, (coord.), op. cit., p. 27. 
Parapetados tras la complejidad hermélica de las leyes económicas, que "los profanos" no alcanzaremos a entender jamás, hacen oidos sordos a quienes desde su misma comunidad científica les descubren falacias en las ciencias económicas $23, \mathrm{e}$ ignoran a quienes desde otras disciplinas denuncian sus límites epistemológicos 24 , proponen una nueva y más equilibrada visión de la economía o simple y llanamente hablan de alternativas al capitalismozs.

\section{El opio capitalista del pueblo}

A Iravés de los más poderosos medios de comunicación de masas y de eficucísimos mecanismos de persuasión, sostenidos y controlados por la orlodoxia económica, van introduciendo el opio capitalista del pueblo y así terminan por impedirnos percibir unos principios muy sencillos, pero falsos, de funcionamienlo, que finalmente no me resisto a transcribir en la clarividente versión de J. M’ Tortosa. A saber:

1) la economía puede y debe crecer indefinidamente; 2) si la economía crece, todos mejoran; 3) si cada cual busca su propio bien, una "mano invisible" (el mercado) logrará lo mejor para todos; 4) el mercado permite la distribución óptima de bienes y precios más ajustados: 5) no tiene sentido plantearse las cosas a largo plazo ya que el sistema necesita que el beneficio se haga efectivo de inmediato; y 6) el papel de los seres humanos es dominar la naturaleza, ponerla al propio servicio... Todos esos principios son falsos ya que: 1) hay límites; 2) la economía puede crecer y, al mismo tiempo, crecer el número de parados y pobres; 3 ) el "ir cada uno a la suya" suele suponer que los más débiles quedan aplastados en esa lucha darwinista; 4) ese mercado de Adam Smith no existe ya que hay mucha información privilegiada, mucho poder, "muchas relaciones personales" que hacen que los participantes en el mercado... scan muy desiguales entre si y que, al final, sólo muy pocos se aprovechen realmente; 5) plantear las cosas a corto plazo puede impedir incluso la supervivencia en el futuro; y 6) prescindir de la naturaleza es suicidarse como especie. Si, a pesar de lodo, aceptamos aquellos principios es porque son necesarios para que: l) se enriquezcan los

22. I. Ramonet, "L'espoir", Le Monde diplomatique, janvier, 1996.

23. Cfr. P. Ormerod, Por una nueva economia. Falacias de las ciencias económicas. Barcclona, 1995.

24. Cfr. H. Assmann y F. Hinkelammert, A idolatria do mercado, Petropolis, 1989; Jung Mo Sung, La idolatría del capiral y la muerte de los pobres, San José, 1991 ; Neoliberalismo y pobreza, San José, 1993; Teología y economia. Repensando la teologia de la liberación y utopias, Madrid, 1996; J. de Santa Ana, La práctica económica como religión. Crítica teológica a la economía politica. San José, 1991.

25. Cfr. D. Scweickart, Más allá del capiralismo, Barcelona-Santander, 1997: I. Zubero. Movimientos sociales y alternativas de sociedad, Madrid, 1996. pp. 89-100, donde puede encontrarse una bibliografia de obras en castellano que defienden la existencia dc alternativas cconómicas y socialcs al capilalismo, n. 5, p. 93. 
ricos de los países ricos; 2) se enriquezcan los ricos de los paises pobres; y 3) se resignen los demás. Y para resignarse, nada mejor que: 1) pensar que las cosas son como son porque así son de su natural (la naturaleza humana es egoísta, todos buscan maximizar su placer, elc.); 2) aceptar los principios porque son muy "racionales" (para to cual nada mejor que las ciencias económicas y el derecho administrativo... o el marxismo); y 3) no plantearse problemas que pongan en entredicho la estructura de poder entre países (ricos y tercer mundo) y dentro de los paises (ricos y pobres). En definitiva, ser un tecnócrata de los muchos que velan por nuestro bien, de los que nos se venden, pero sí se alquilan. Por supuesto, al bando vencedor 26 .

\section{No demonizar el mercado}

Dicho todo esto, hemos de ser capaces de sortear el riesgo de demonizar el mercado. Este peligro es muy real y muchísimos discursos y prácticas cristianas progresistas no han sabido evitarlo, precipitándose "bellamente" en el arrecife de la ineficacia histórica. Es cierlo que el mercado no es una "chistera" de la que surgen realidades humanas gracias al inПujo de la varita mágica de la libre competencia. Pero el mercado como instilución y la razón económica como herramienta nos son absolutamente imprescindibles para luchar eficazmente contra la pobreza del mundo y posibilitar una vida digna a la mayor parte de la humanidad. "Nos equivocaríamos si redujéramos el significado del mercado a su dimensión económica; en él se reconoce el emblema de la liberlad individual y de las instituciones de libre adhesión; es el símbolo de las virlualidades democráticas"27.

Pero del dicho al hecho hay un enorme trecho que recorrer. Esas virtualidades están cautivas y necesitan ser liberadas para convertir el mercado en un escenario de la solidaridad y la justicia en libertad. Ello exige no sólo una urgente redistribución de las rentas y de la riqueza, sino también una transformación del sistema produclivo que la haga factible, y profundas reformas en la estructura cconómica y política. Pero, iseremos capaces de sustituir la actual lógica "sacrificial" del sistema (en favor de los intereses de unos pocos privilegiados y a costa de la vida de las mayorías pobres) por la de la solidaridad compasiva (en contra de los intereses de los primeros y a favor de la vida de todos)? ¿Conseguiremos ponerlo al servicio de una humanidad realmente fralerna y no victimaria? ¿Sabrcmos sustiluir la fuerza hegemónica de

26. La pobreza capitalisła, Madrid, 1993, pp. 10-11.

27. J. García Rocil, "Compasión, cquidad y justicia". Iglesia viva 156, 1991, p. 575.

28. Enirc el 30 de junio y el 4 de julio de 1997 Iuvo lugar en lima el 1 Simposio Internacional sobre la "Globalización de la solidaridad", con la participación de expertos cconomistas. asi como de mais de 150 parlicipantes de 32 nacioncs de todos los contincnles. Puede verse el documento finil en Páginas 146, agosto 1997. pp. $110-112$. 
la globalización del mercado por la de la globalización de la solidaridad?2k. En esta incertidumbre se encierra el principal problema de toda la humanidad. En estas circunstancias, ser conservador implica aceptar la condenación, la exclusión y hasta la muerte de la gran mayoría de la humanidad, que ha quedado fuera de la modernidad y sus beneficios 29 .

\section{El cristianismo ofrece una mística, una perspectiva y unas orientaciones prácticas para este combete}

Ni las iglesias, ni el cristianismo tienen en sus manos la solución. Sin embargo, son portadores de una "conciencia excedente", nacida de su confianza en que las posibilidades inédilas e inauditas de Dios son viables en la historia. Esta convicción es fuente de resistencins a la complicidad con el espíritu del tiempo ("el entreguismo" como consecuencia del espesor del presente), y de sueños emancipalorios que fuerzan a ir siempre más allá y a sobrepasar el sistema económico vigente, sustituyéndolo por otro que haga factible la vida de los pobres. Desde la perspectiva de los pobres, la fe descubre la presencia de Dios del lado de los sacrificados y se niega a aceptar que la lógica que los excluye sea la lógical que tiene la razón. Perlrechado de este modo, el cristianismo ha de estar dispuesto a introducirse (como palabra y espíritu) en las intrincadas condiciones de nuestro mundo para transformarlo en favor de la juslicia y la vida.

\subsection{La mística de la confianza en un amor incondiciona!30}

\section{Sin fe no se puede transformar el mundo}

La humanidad clama por un sentido o por un nuevo orden mundial que no parece posible. Sin embargo, "conocemos todo lo que prácticamente se puede conocer del funcionamiento de las economías. Sabemos cómo eliminar el hambre. Sabemos cómo crear empleo. Sabemos cómo se puede redistribuir la renta. Sabemos qué es lo que sucede con los 'económicamente inúliles'. Tenemos los conocimienlos y los deseos. Sólo falta el poder"3l. Si "poder es querer", podríamos decir: sólo nos talta "querer". Pero la cuestion es aún mucho más compleja. La conversión de "este querer" en "poder" cultural, económico y político reclama algo más hondo que la voluntad moral. Hoy nos afanamos por dar con aquella molivación que sea capaz de sostencr ideales colectivos altruistas entre los poderosos ciudadanos de "la cullura de la satisfacción", y de disponerles a pagar libremente el alto precio que les acarreará hacer efectivo ese

29. Cfr. L. Boll, Con la liberiad del evangelio, Madrid, 1991, p. 19.

30. Sigo muy de cerea lo que eserilí en otra ocasión: "Una religión al servicio de lo inolvidable". Ig/esia viva. 184-185, 1996, pp. 371-383.

31. D. Anisi, "La sonrisa de Keynes", en AA. VV., La larga noche neoliheral.... pp. 296-297. 
"querer": renunciar a sus deseos ilimitados en favor de las necesidades básicas de las mayorías pobres (comida, bebida, salud, vivienda, trabajo, educación, elc.). Cuando se piensa a partir de los deseos no hay límiles, se busca lo ilimitado. Y cuando se desea lo ilimitado nunca sobra nada para repartir, siempre falta 32 . En esas condiciones compartir solidariamente con los pobres se convierte en un querer imposible. He aquí el gran obstáculo: falta la fuerza de una gran convicción que permita cambiar a la óptica de la necesidad, y, ya se sabe, sin fe no se puede transformar responsablemente el mundo.

\section{El miedo a la muerte, energía solidaria}

Las amenazas objetivas que la aclual siluación mundial encierra son de lal magnitud que han comenzado a afectar también y seriamente los intereses de los poderosos y de los países centrales. Este cambio de situación ha convertido nuestros problemas finiseculares (pobreza, ecología, amenaza del caos, etc.) en relevantes para ellos. El miedo guarda la viña de la humanidad, se ha comenzado a pensar. Nada con mayor poder para salvaguardar la vida que los intereses o el amor propio. $Y$ así se anuncia a toda página en los diarios de mayor difusión de algunos países del norte.

El prestigioso intelectual francés, E. Morin, lambién se ha sumado a esta corriente. Sugiere una (nueva) religión sin dioses, pero con un sentimiento místico y sagrado, abierta a la compasión y portadora de un evangelio de la perdición. La humanidad constituye una comunidad de destino de muerte y nuestro pequeño planeta perdido es nuestra "nuestra tierra-patria". Esta necesidad se convierte en la mejor virtud para actuar moralmente y evitar que la muerte sobrevenga antes de tiempo. De la cerleza de no poder escapar de la perdición y del redescubrimiento del planeta tierra como techo, casa y palria de la humanidad emerge la necesidad de una "fuerza comunicanle y comulgante" de "religación entre los humanos", que con el esfuerzo fraterno común evite el desastre de la mucrte prematura de la humanidad (lo peor), y prosiga (lo mejor posible) la hominización y la civilización de la tierra.33.

Que el miedo a la muerte prematura universal o su versión menos descarnada del amor propio sean capaces o no de producir esa promelida religación entre los humanos o una afirmación de la vida que alcance lambién a quienes masivamente la pierden hoy antes de tiempo, es algo que está por ver, pero no seré yo quien desautorice esas propuestas. Sobre todo porque, al haber surgido en un espacio culturalmente cristiano, ponen en evidencia la lalta de capacidad solidaria del cristianismo vivido y plantean la urgencia de la vuclta a un cristianismo vivo.

32. Cfr. Jung Mo Sung, op. cil., p. 7.

33. Cfr. E. Morin y A. B. Kern, Tierra-Patria, Barcelonil, 1993, pp. 205-219. 


\section{La mistica del cristianismo vivo}

Este sí posee capacidad energética para establecer una "religación" solidaria entre todos los seres humanos, y puede suscitar entre sus fieles algo así como una solidaridad vicaria, es decir, una disposición democrálica a desvivirse o a perder anticipadamente (mucho de eso que configura lo que habilualmenle se llama la buena) vida con el objetivo de consiruir el hogar común de la humanidad.

La tradición cristiana habilita para la entrega de la propia vida en la lucha por erradicar la pobreza del mundo. La explicación no ha de buscarse -como E. Morin y muchos cristianos con él creen- en la promesa de la recompensa de la resurrección. La motivación cristiana más eficaz para ese tipo de proexistencia es un Dios que es Buena Nolicia para los pobres. Tampoco sus imperativos morales y su talante fraternal constituyen - como apuntan muchos de los patrocinadores de la reorientación solidaria de los países ricos- su aporte más radical. Su recurso más decisivo es la posibilidad que ofrece de construir la existencia personal y colectiva desde la confianza en un Dios Amigo de los seres humanos.

La religión cristiana entrega una forma de eslar presente en la realidad y de enfrentarse con ella, cuyo desencadenante fue la historia fraterna de Jesús de Nazaret. Su inspiración solidaria brota de un sentido de la realidad del mundo, que el gran samaritano de la humanidad dolienle (cfr. Lucas 10, 25-37) encontró sembrado en la finca de la historia (cfr. Maleo 13, 3-23), comunicó a los hombres (cfr. Marcos 1, 15) y valoró como un hallazgo tan precioso que aún la mayor de las renuncias para adquirirto no impide hacer el más barato y seguro de los "negocios" (cfr. Matco 13, 44-46).

La convicción fraterna y solidaria de Jesús vive y se regenera permanenlemente en la experiencia del advenimiento del reino de vida, cuyo origen se encuentra en la proximidad de Dios que le hace $\mathrm{Hijo}$ y en su compromiso con la vida de los pobres, sus hermanos (cfr. Mateo 11, 2-6). Dios irrumpe como posibilidad de una vida humana plena de alcance universal, pero ésta va brotando como realidad desde la atención a las necesidades hislóricas de "los-sin-vida" de la tierra. Los pobres y su causa son el lugar dónde Dios ha depositado definitivamente su gloria vivificante. Jesús, tomando la condición de los pobres y haciéndose uno de tantos ( $c f r$. Filipenses 2,7), se la devuelve al Padre procurando que la vida entre ellos cunda sobreabundantemente.

Jcsús tuvo que cnfrentar el abismo de la muerle y asumir la incertidumbre que provocó el fracaso de su causa fraterna. El poder de un sistema idolátrico, antilético a su pretensión, parecía derrolarla definitivamente. Pero entre la lógica de la desesperación o la de la resignación que parecian inesquivables, eligió otra alternativa: morir como había vivido, abandonando confiadamente su causa y su 
propio destino personal en las manos del Dios Amigo (cfr. Lucas 23, 46). Desde entonces, un rumor en torno a él ha recorrido la historia: Dios le ha devuelto la vida (cfr. Hechos $2,23-24 ; 3,13-15)$ y este acontecimiento en forma de promesa tiene alcance universal ( $c f$. Hechos 2,39 ). Su resurrección anuncia que el de Jesús es el "último sacrificio". Una historia nueva ha surgido en la que todas las necesidades humanas pueden ser satisfechas. Ha irrumpido el tiempo mesiánico de abundancia para los pobres y de gracia para las víctimas. La cercanía del Dios de vivos (cfr. Maleo 22, 32) abrió así una brecha definitiva en la fatalidad del circuito de la muerte e impidió que la realidad se pueda declarar absurda por no poder desembarazarse de ese destino ruinoso. ¡El Dios amigo de la vida (cfr. Sabiduría 11,26 ) es mayor que la perdición!

\section{El "poder" solidario de la confianza}

Cuando el cristianismo proclama y vive de esta convicción no "está mirando para otro lado". Cuando la celebra no to hace para distraer el miedo que le produce el zarpazo inevitable de la muerte. Cuando propone el amor a los hermanos como su verificación histórica (cfr. 1Juan 3,14$)$ no está incilando a "la fuga hacia adelante". Simplemente quiere dar cuenta, sin ningún tipo de fanatismo, de lo que "ha vislo" desde la perspectiva de Dios. La situación de una humanidad sujeta al egoísmo y sometida a la muerte se puede contemplar con dolor, pero sin impolencia; con las señales de derrota, pero sin los síntomas de la resignación, porque el don del Espíritu ha inaugurado para ella un régimen nuevo de filiación y fratemidad. Consecuentemente, se puede ser consciente del fracaso de la razón y de la supuesla bondad de la liberlad de la especie humana y, al mismo liempo, abrigar la esperanza en sus posibilidades de fratemidad, porque ha sido liberada por el Espíritu de Jesús de la decadencia para alcanzar la gloria de los hijos de Dios; se podrán escuchar los gritos de los pobres y compadecer los sufrimientos de la creación y percibir en todo ello los lamentos y los dolores del Espíritu de Dios en su difícil parto de la nueva creación. El secreto consiste en aceplar la invilación a abismarse en el Misterio Absolulo de Amor que es Dios (cfr. Romanos 8, 1-35).

En el cristianismo, la fuerza para la religación entre los humanos no nace del temor a la muerte prematura, sino de la confianza en la vida plena. Los vínculos de la fraternidad no brotan de la constatación de estar inemediablemente perdidos, sino de la experiencia agraciada de vivir indestructiblemente hermanados "en buenas manos". El impulso para compartir la suerte de los pobres no surge de un problemático reconocimiento de la tierra como casa común, sino de la intuición creyente de que el hogar de todos tiene ya suelo firme donde construirse: el regazo de Dios. El estimulo para la solidaridad compasiva no se recibe del ideal de convertir nuestro planeta en puerto de salvación, sino de la revelación de que Dios ha creado la humanidad para que 
sea comunión fraterna de felicidad y vida ya en la tierra, la casa solariega de los hijos del Padre, y la ha destinado a la plenitud de la patria trinitaria.

La confianza ilimitada en el Amor incondicional provoca un "poder" descomunal de [ratemidad y constituye la fuente más profunda de recursos energélicos para pensiar y actuar solidariamente.

\subsection{La realidad bajo la mirada del Amor incondicional}

El cristianismo no patrocina ningún viaje gratuito al Olimpo de los dioses, sino una mística de ojos abiertos (J. B. Metz), que dilata, como si de un colirio se tratase, las pupilas de los ojos para ver (cfr. Apocalipsis 3, 18) y llorar el horror Iremendo del infierno de la pobreza. El cristianismo parlicipa así de la perspectiva de la mirada del Amor incondicional, que desvela la mentira de la realidad y revela sus oportunidades históricas.

\section{La idolatria del mercado}

Ya hemos indicado cómo la idcología neoliberal tiende a absolutizar el mercado, hasta el punto de convertirlo en el mélodo y fin que gobierna las relaciones de los seres humanos. Sus proclamas victoriosas y jubilosas recuerdan unas palabras del profela Isaías, que anunciaban la presencia de Yahweh (cfr. 40, 10-17): “¡Ahí está vuestro "dios'!". El mercado llega con poder y su brazo manda. ¿Quién, como ćl, midió la asignación de los recursos productivos escasos de forma que la producción alcanzara la máxima posible y fuera la más adecuada a las necesidades de la sociedad? ¿Quién abarcó la sabiduría del "djos-mercado" y como consejero suyo le enscn̄ó? ¿Con quién se aconsejó, quién le explicó y le enseñó la ciencia de la produclividad y el camino de la racionalidad económica le mostró? Las naciones son nada ante él, valen lo que el polvillo de la balanza de pesar. La vida de los pucblos pesan en sus decisiones lo que un grano y sus recursos humanos y nalurales no bastan para su holocausto. En su presencia todos los gobiemos de las naciones es como si no existicran". Pcro, cuando se analizan los resultados de sus polílicas económicas, se puede comprobar que, a diferencia del Dios de vida, ni con el "dins-mercado" vino su salario a los páises pobres, ni le precedió su recompensa, ni alivió siquiera la deuda extema, sino todo lo contrario. Siguiendo con la imagen biblica podríamos decir que, en lugar de dirigir, tralar con cuidado y llevar solidariamente en su seno a esos pueblos hasla la ticrra de la liberlad y de la vida, los "hirió y degolló el rebaño".

La reciente historia de la econonía de mercado muestra cómo la legitimación incondicional y absoluta del sistema ha reforzado y blindado su tendencia idolátrica. En nombre de una necesidad racional "científica" se ha ignorado la exislencia de bicnes que, por su naturalcza, no son ni pueden ser simples mercancias. Se ha construido el mercado, de espaldas a la hipoteca 
social de la propiedad privada, como un escenario exclusivo para los beneficios y los capitales y sin control de las fuerzas sociales y de los gobiemos. El resultado final son los sacrificios humanos. El número de pobres ha aumentado alarmantemente y su situación de humillante dependencia se ha agravado con el paso del tiempo.

Esta nueva religión, revestida de carácier científico y secular, es incapaz de aceptar que exista algo que le sea debido al hombre porque es hombre. Sus productos solamenle son vendibles. Están pensados para satisfacer exclusivamente necesidades solventes. Consecuentemente el (mal llamado) libre mercado se convierte en un instrumento ineficaz para colocar recursos y responder eficazmenle a necesidades de la mayoria de la humanidad. A los pubres -insolventes en el mercado - no se les ofrece ninguna posibilidad real de sobrevivir y de participar activamente en el bien común de la humanidad: su presente y su futuro es la muerte 34 .

Las iglesias, en la medida que recuperen su tradición "no-sacrificial" y revitalicen su tradición de amor al prójimo35, se encontrarán denunciando la falsedad de este "ídolo" de muerte, y serán llevadas por "el celo de la casa (oikos) del Dios de vida" a combatir contra su poder y en favor de una sociedad mundial, en la que los pueblos pobres puedan sentarse como iguales en la mesa común de la humanidad y compartir las decisiones con los grandes del mundo. Me parece una cuestión decisiva para la evangelización. Y por ello no alcanzo a entender la ausencia del tema de la idolatría y la falta de entidad de la opción por los pobres, sus víctimas, en el documento Instrumentum laboris de la Asamblea Especial para América del Sínodo de los Obispos 36 . Ambos temas condicionan estrechamente el anuncio de Jesucristo vivo y el encuentro personal con él. El sistema idolátrico hace que esas prácticas cristianas sean arriesgadas y crucificadas. Así lo he podido comprobar personalmente todavía hace pocas fechas: en tiempos de paz muchos guatemaltecos ven peligrar su puesto de trabajo en las fincas de café por ser católicos y querer caminar por la vida "con la potencia de la verdad acerca del hombre y del mundo, contenida en el misterio de la encarnación y de la redención" y "con la potencia del amor que irradia de ella"37. Los pobres, su perspectiva y su experiencia, su esperanza de salvación y de liberación, son el criterio de loda palabra y acción auténticamente cristianas 38 . También del anuncio del evangelio y del encuentro con Jesucristo vivo.

34. Cfr. C. A. 30-35.40.43.

35. Cfr. H. Assmann (cd.), Sobre idolos y sacrificios. René Girard con teólogos de la liberación, San José, 1991.

36. Cfr. "Encuentro con Jesucristo vivo, camino de conversión, de comunión y de solidaridad", Ecclesia 2.863 y 2.864 , oclubrc 1997 , pp. $1540-1550$ y $1578-1590$.

37. M. Kehl. La Iglesia. Eclesiología católica, Salamanca, 1996, p. 222.

38. Cfr. ibid., p. 222. 
Afirmar, como hace el Instrumentum laboris, que "sólo a través de una equilibrada comprensión de las dos naturalezas y de la perfecta unidad de las mismas en la segunda Persona de la Santísima Trinidad puede el ser humano aproximarse al misterio de Jesucristo, presente en el hoy de la historia como Cabeza de la Iglesia, que es su Cuerpo"39, convierte la tarea de la iniciación creyente y de la experiencia fe en una labor académica y, lo que es mucho más grave, parece enmendar la plana a Dios que quiso conceder graciosamente un privilegio hermenéulico a los pobres y sencillos en orden a reconocer la verdad de su revelación (cfr. Mateo $11,25-28$ ).

\section{El pecado estructural}

La praxis del sistema económico hace más plausible el reconocimiento de la existencia de estructuras de pecado. Desde hace algunas décadas, la leología viene hablando en este senlido. Juan Pablo II ha alertado sobre su naturaleza. Tras analizar la siluación de extrema pobreza en que vive gran parte de la humanidad, afima que todo eso no sucede por responsabilidad de las poblaciones indigentes, ni mucho menos por una especic de fatalidad dependiente de las condiciones naturales o del conjunto de las circunstancias, sino por la existencia de mecanismos económicos, financicros y sociales que acumulan riqueza en unos lugares y empobrecen a los restantes.

Esos mecanismos generan estrucluras de pecado que provocan muerte en sus más variadas versiones 40 . Por supuesto, pérdidas millonarias de vidas humanas, pero también otras situaciones de mortandad: multiplicación de masas urbanas sin trabajo o que subsisten en empleos inestables y poco productivos; quiebras de miles de pequeñas y medianas empresas que abortan además la capacidad de los agentes sociales de interactuar socialmente; la movilidad y la presión laboral que convierten en residual el tiempo familiar y vecinal del trabajador y hiere sus lazos primarios de relación; el desplazamiento forzado de poblaciones campesinas e indigenas que hace vulnerable y destruye sus tradiciones culturales y espirituales; la pérdida de conciencia democrática como consecuencia del despilfarro de los ricos, el crecimiento de la desigualdad y el escándalo de la corrupción, el aumento de la criminalidad y de la violencia urbana provocada no pocas veces por el hambre y la desesperación más profunda; la expansión del narcotráfico basado en productores campesinos, cuyos productos tradicionales han quedado fuera de la competencia del mercado; desaparición de la seguridad alimentaria; desestabilización de las economías nacionales por los tlujos libres

39. N. 8. El énfasis es nuestro.

40. Cfr. SRS 9f.16c.36. 
de la especulación internacional; desajustes en comunidades locales por proyectos de empresas multinacionales que prescinden de los pobladores, elc.41.

Estamos ante la lógica sacrificial de un sistema de muerte. La mirada de Dios revela su carácter de pecado estructural. Dios prohíbe al cristianismo que se refugie en una concepción puramente personal del pecado y de la conversión, y que mantenga una mirada inocente o ingenua frente a la realidad económica. Desde la perspectiva divina, la bondad de un sistema económico no depende ya de que sea un espacio de libertad, sino que se mide por la manera solidaria o no de producir sus resultudos (la cuestión de la dislribución de la riqueza), aunque éstos sean menos espectaculares desde el punto de vista de la eficiencia productivi.

Una Iglesia que se tome en serio "la mistagogía de la conversión, de la comunión y de la solidaridad", ha de aprender a practicar la ley de vida de Jesús, su Mesías y Señor: quitar el pecado del mundo pasa por cargar con el pecado del mundo. De aquí que el cristianismo reivindique el sentido humano de entregar la vida y la liberlad en favor de la gestación de un nuevo modelo coonómico. La experiencia de vivir permanentemente bajo la mirada benevolente de Dios le permite saber que "el ser-con" y "el ser-para" es la primera verdad de todo ser humano con independencia de su calidad ética

La auléntica condición humana se despliega en la pro- existencia, es decir, en la renuncia al desarrolio de la propia voluntad de poder, que lleva fatalmente il la negación o a la asimilación del otro, y en el arte de dejar y abrir sitio al otro, al exlraño, al no-solvenle (diriamos en términos económicos). Es en esle ejercicio donde la libertad humana alcanza su más plena expresión. Si la libertad humana no debe entenderse de ninguna mancra como liberlad para la coacción, tampoco su verdad radical responde al paradigma del liberalismo económico: la libertad de determinación. Una libertad así concebida se ha manifestado históricamente incapaz de superar la lógica del dominio y de la posesión. La sabiduría cristiana habla de la libertad como libertad de comunión, como capacidad de determinarse en apertura al otro y religación con el otro: el hombre es cabalmentc libre, cuando asume la condición de guardián de su hermano o de buen samaritano.

\section{La historia bajo la promesa}

En plena oscuridad histórica, la mirada del Dios de vida da paso al prescntimiento de la posibilidad de un futuro nuevo para los pobres. La promesa de Dios no está medida por la capacidad de las esperanzas humanas. Esta gratuidad inaudita orienta permanentemente la esperanza cristiana en orden a

41. Cfr. "Carla de los provinciales lalinoamericanos de la Compañía de Jesús. El neoliberalismo en América Latina", Caria a las /glesias desde El Salvador. 367, $1996,13$. 
reconocer que la realidad ya está marcada con la impronta del evangelio, y le invita a explorar y explotar al máximo el rico filón de lo todavía inédito, pero ya viable de la utopía de la ciudadania universal. El cristianismo es una fe siempre abierta en las posibilidades de la historia, que se opone tenazmente a cualquier conato de interpretarla optimistamente. Creer en la proximidad del reino de Dios es dejarse encantar por la promesa de que esta historia, también en las puertas del s. XXl, puede dar de sí algo diferente y alternativo (es decir, que puede revertirse). Creer en el don del Espíritu es recobrar la libertad de disentir de la opinión mayoritaria ("sólo podemos aspirar a ir tirando") y romper con la evidencia común ("el futuro que nos aguarda será más de lo mismo").

En medio de esta sociedad amnésica y posmoderna, el crislianismo despierta la memoria colectiva de las causas que ayudaron a vivir y morir con dignidad en el pasado, recupera sus esperanzas y alienta la resistencia crílica contra las fuerzas de la barbarie. Modestamente, intenta aportar un granito de arena a la conslrucción de una cultura de la participación y la solidaridad. Esta fe cristiana es capaz de suscilar hombres y mujeres, expertos en la élica herida de la compasión, diestros en la promoción de una acción social de resistencia que convierta en realidad parcial y anticipativa el mundo alternativo que seguimos soñando con el Dios de la promesa. Seguramente todas sus realizaciones "son cosas chiquitas", como diría Eduardo Galeano. "No acaban con la pobreza, no nos sacan de la espiral de la violencia, no socializan los medios de producción y de cambio, no expropian las cuevas de Alí Babá. Pero quizá han tenido capacidad de desencadenar la alegria de hacer y de Iraducirla en actos. Y al fin y al cabo, acluar sobre la realidad y cambiarla, aunque sea un poquito, es la única manera de probar que la realidad es transformable".

\section{Fuera de los pobres no hay salvacion}

Todavía somos muchos los que seguimos pensando que a pesar de sus cantos de victoria, dentro de la economía de mercado no hay salvación. Nos resulta "inaceptable, repetimos con Juan Pablo II, la afirmación de que la derrota de! socialismo deje al capitalismo como único modelo de organización social". Preferimos afirmar, otra vez con Galeano, que "el socialismo no murió, porque todavía no era", y creer con él que "hoy es el primer día de la larga vida que tiene que vivir".

Pero además la "forzosidad" de los hechos y la terquedad de la realidad muestran que $\sin$ los pobres no habrí salvación. Como he repetido en otras ocasiones, el drama de ese humanismo idólatra, devaluado, indoloro y apático que nos envuelve, consiste en querer organizar la socicdad etsi pauper non daretur, sin percalarse de que exira pauperes nulla salus. Vincular el fuluro de la humanidad al destino de los pobres se ha hecloo una necesidad hislórica, que el neoliberalismo no sabe o no quiere reconocer $y$, por ello mismo, sus 
propuestas de fuluro no hacen camino, sino que encierran a la humanidad en las aporías del presente. La sabiduría cristiana no puede menos que percibir a los pobres y su liberación como una oportunidad histórica de salvación para toda la humanidad42. Ella sabe que la salvación escatológica del Dios de vida está vinculada a su destino y a su causa.

\subsection{Prácticas intempestivas de resistencia y solidaridad}

El cristianismo, lo hemos visto, suministra "razones" para ponerse al servicio de lo inolvidable: la historia interminable de las víctimas. Dios mismo ha converlido la cuestión de la responsabilidad con el prójimo en la cuestión religiosa por antonomasia. La misión del cristianismo en el mundo estriba en aceptar al pobre como un absoluto al que se le debe un amor ilimitado e incondicional como a Dios mismo y hacerse su súbdito. La cuestión de la salvación no consiste ya en buscar un salvador y reconocerlo como tal, sino en preocuparse de aquellos que padecen necesidad y reconocerlos como alguien que tiene derechos sobre nosotros ( $c$ fr. Mateo 25, 31-46)4?.

Pero, dada la identidad y la resistencia del sistema de globalización neoliberal, ¿cómo podrá el cristianismo configurar efeclivamente su servicio a las victimas? La respuesta es muy amplia y seguramente nos llevaría mucho más lejos —en tiempo y espacio— de lo que permite este trabajo. Me limitaré a sugerir algunas cuestiones.

\section{Estilos solidarios de vida e Iglesia de los pobres}

El cristianismo vivo es memoria viviente, conflictiva y subversiva de las víctimas del sistema. Una religión al servicio de lo inolvidable ha de saber configurarse como interrupción crítica de la lógica sacrificial dominante. El proyecto de nueva evangelización que se marca como objetivo alcanzar una civilización del amor, en palabras de Juan Pablo ll, debería tomarse muy en serio las reflexiones proféticas de Ignacio Ellacuría sobre la civilización de la pobreza44, para no perderse en consideraciones sublimes, pero que nunca aterrizan en este suelo nuestro, lan contaminado por la toxicidad letal del orden que todo to domina.

42. "Scrá neccsario abandonar una mentalidad que considera a los pobres -personas y pueblos- como un fardo o como molestos e importunos, ávidos de consumir lo que olros han producido... La promoción de los pobres es una gran ocasión para el crecimicnlo moral, cultural c incluso cconómico de la humanidad cntera", Centesimus annus 28.

43. Cfr. J. Moingl, El hombre que venia de Dios, vol. II. Bilbao. 1995, pp. 149-156.

44. Cfr. "Ulopia y profelismo", cn I. Ellacuria y J. Sobrino (cds.), Mysterium Liberationis. Concepros fundamentales de teologia I. Madrid, 1990. pp. 246ss. 
Cada día son más urgentes y necesarios los estilos intempestivos de vida austera y solidaria, tanto a nivel personal como comunitario, que hagan correr "rumores" del Dios solidario. El crislianismo como apremio y fermento de una comunidad humana de destino fraterno no existiría sin las historias solidariamente evangélicas. Este final de milenio se ha visto agraciado por la presencia de "una gran nube de testigos" ( $c f r$. Hebreos 12,1$)$ del Dios de los pobres, a veces al precio de su propia vida. La vida de la Iglesia, y muy especialmente de la Iglesia Latinoamericana, ha sido acompañada e iluminada por una cosecha abundante de historias de mártires. Ellos han acreditado el evangelio de Dios del modo como lo hizo Jesús: entregando su vida por la causa de los pobres del reino de Dios45. Sin embargo, hemos de reconocer que, globalmente considerada, la Iglesia necesita convertirse y creer en la buena nueva del evangelio de la solidaridad. Demasiadas veces sus clarividentes discursos oficiales van acompañados por unas prácticas institucionales y personales de solidaridad tan baratas que aquéllos suenan a ridículo frufrú en medio del griterío ensordecedor de las víclimas del sistema sacrificial dominante.

Este déficit plantea una cuestión eclesiológica delicada: su propia condición de sacramento de salvación ( $c f r$. LG 48; AG 1 ) en un mundo como el nuestro, estructuralmente injuslo. La cficacia de su carácler de "signo e insırumento" de una salvación comprendida como "unión íntima con Dios" y "unidad de todo el género humano" (cfr. LG 1), no está absolutamenle garantizada por el Espíritu que la habita. Este dinamismo sacramental también depende de la calidad solidaria del testimonio eclesial. Una vez más hemos de recordar que Ja opción por los pobres constituye el fundamento, el signo que unifica y define todas las realizaciones sociales en el anuncio del evangelio, en la celebración de la eucaristía y en la diaconía dentro y fuera de la lglesia. Esto significa que los contenidos y los actos centrales de la fe van unidos a ia situación concreta de los pobres y se entienden como remedio y curación para ellos. Los pobres que son en cierto modo el "sicramento" de iniciación de la voluntad salvífical universal de Dios (cfr. Maleo 25, 40ss), le transfieren esa sacramentalidad a la Iglesia46.

45. Como católico europeo que ha recibo agradecido tanto "espiritu" dc testimonio de csos mártires, no pucdo comprender, y hasta me resulta cscandaloso, que cl documento para la Asamblea Especial para América del Sínodo de los Ohispos no los mencione, al menos entre los signos concretos del despertar religioso de la Iglesia en América (cfr. n. 25) o como exprcsión de su cunciencial solidaria (cfr. n. 53-55).

46. Cfr. M. Kchl, op. cii., p.222. 


\section{La coalición con las víctimas}

Las proclamas contra el neoliberalismo se multiplican. Quizás la convocatoria más realista por su talante utópico sea la del Frente Zapatista de Liberación Nacional:

A todos los que, sin importar coloses, razas o fronteras, hacen de la esperanza arma y escudo... los convoca al Primer Encuentro Intercontinental por la Humanidad y Contra el Neoliberalismo. Creo que lo de menos es saber la fecha exacta de ese encuentro. ¡Lo importante es saber que esta resistencia es permanente, poélica (creativa), política y eternamente en favor de la vida!47.

Con enorme clarividencia y realismo se ha hecho notar la necesidad de un movimiento mundial a favor de los derechos civiles económicos. La práctica solidaria del cristianismo se orienta en esa dirección y debería contribuir a la creación y fortalecimiento, a todos los niveles -local, regional, europeo y mundial-, de una coalición entre las víctimas del sistema y los movimientos sociales $4 k$.

El campo de acción es muy amplio y empieza por reconocer la existencia de alternativas a pequeña escala (de economía informal y autosuficiente, de organizaciones populares, elc.) para insertarse en ellos. Pero quisiera destacar tres escenarios de lucha especialmente importantes.

\section{El sistema educativo}

La integración ideológica de las masas al sistema de mercado se realiza por los media, las escuelas y las universidades. Enfrentarse con éxilo con el poder de esos medios y conseguir educar para la libertad solidaria, no es tarea fácil. La memoria de Paulo Freire, infatigable luchador por la educación liberadora, fallecido este año, y la reciente publicación del Informe a la UNESCO de la Comisión Internacional sobre la educación para el siglo XXI, presidida por Jacques Delors ${ }^{49}$, nos recuerdan que la sabiduría y la compasión son necesarios para que nuestros conocimienlos y tecnologías nos ayuden a aprender a vivir junlos $y$ aprender a ser humanos en el siglo XXI.

La Iglesia católica, a través de su tupida red educativa (desde la escuela a la universidad) debe sumarse a este empeño, aunque haya de reconocer que, en

47. "Primera Declaración de la Realidad contra el Neoliberalismo y por la Humanidad", Carla a las Iglesias desde El Salvador, 377, 1997, p. 9.

48. Cfr. U. Duchrow y M. Gūck, "Alcrnalives á l'ćconomic capitaliste mondiale. Repères bibliques et approches politiques pour vaincre une économie que menace la vie", Liaisons Intermationales 80, 1994, pp. 2-11.

49. Cfr. La educación encierra un tesoro. Madrid, 1996. 
muchos casos, por no contar en su tejido educalivo con células de resistencia al sistema neoliberal, suele ser muy frecuentemente su compañera de viaje. Pero muy concretamente me interesa destacar que las universidades católicas, sus facultades e institutos economía y ciencias empresariales y sus departamentos de ética, podrían jugar un papel decisivo en el fortalecimiento de la coalición entre víctimas y movimientos sociales. Ello les obliga a hacerse sin tapujos preguntas como éstas: ¿cuáles son sus objetivos formativos? ¿qué intereses están sirviendo?, ¿sus alumnos se capacitan solidariamente para integrarse en la coalición o profesionalmente para fortalecer el sistema?, ¿qué proyectos de investigación proponen y aprucban?, ¿en cuáles invierten sus recursos humanos, matcriales y financicros más importantes? No se trata de buscar respuestas simples y demagógicas, sino de ser humanamente lúcidos y cristianamente honrados. De su contestación está dependiendo en gran medida el que la red educativa católica en general y la universilaria en particular tengan o no la calidad de evangelio y estén o no al servicio de la evangelización de nuestro mundo.

\section{El ámbito de la politica}

Todos sabemos lo desprestigiada que está la aclividad política, pero necesilamos redescubrirla como medio indispensable para alcanzar un nuevo orden económico mundial. Nuestro debale no debe empantanarse en un planteamiento dilemálico enire parlidos políticos y nuevos movimientos sociales. La promoción de la justicia nunca podrá realizarse plenamente sin un proceso de profundización de la democracia, que garantice eficazmente la promoción de la vida entrc los pueblos y los grupos humanos, que están excluidos o marginados y no entran en el círculo del desarrollo económico y humano. Nuestro debale, por tanto, debe estar encaminado a resiluar la political y la razón por encima de la economía para posibilitar un nuevo escenario político, en el que ya no sea posible la subordinación de lo político a la ciega lógica de los mercados económicos50.

Se trata de claborar una nueva "economía política" en la que se vayan haciendo factible cosas lan necesarias como la reorientación de los instrumentos de organización social, según una concepción adecuada del bien común con referencia a toda la familia humana, el control internacional del sistema económico que supere su déficit de democracia, el diálogo y la concertación entre los países, y la democratización de los organismos internacionales para que estén igualmente representados los intereses de los pucblos y países que tienen escaso peso en el mercado internacional51. El tránsito de una sociedad

50. Cfr. R. Espasa, "Nucva cultura cconcimica. nucva pobreza", en AA. VV.. 1996. “Año de la erradicación de la pebreza", Barcelona, 1906, pp. 26-27.

5I. Cfr . CA 58 . 
capitalista avanzada a la democracia económica necesita de un movimiento político poderoso, inteligente y realmente activo así como la revitalización del propio movimiento sindical. Solamente así se podrá poner en peligro a una clase dirigente tan profundamente afianzada como lo está la clase dirigente en una sociedad capitalista avanzada52.

"Pasar de política" es renunciar de hecho a estos objetivos y abandonar a su suerte a las víctimas del sistema. Redescubrirla, valorarla y parlicipar en todos sus niveles (municipal, aulonómico, nacional, europeo) es una exigencia de la solidaridad y una forma de resistir e ir venciendo la lógica inmisericorde del sistema. Esta vigorización de la vocación política debe comprenderse como una exigencia del seguimiento histórico de Jesús.

\section{El ámbito de la economia}

La economía es un ámbito de la realidad en el que la presencia de la militancia cristiana está casi inédita. Es cierto que está repleto de cristianos de todas las confesiones, pero en realidad son militantes del liberalismo, del neoliberalismo o simplemente de su profesión, entendida de manera aséptica en relación con las relaciones solidarias.

Una razón habrá que buscarla en el modo privado como gran número de cristianos viven su fe. Pero otra es, sin duda, el miedo a ser víctima del sistema. Acabo de leer un texlo confirmatorio de Luis de Sebastián, que no me resisto a transcribir, dada la experiencia del aulor.

Eslos mecanismos [de la ortodoxia y la ortopraxis económica] emplean, en última instancia, la fuerza bruta del dinero para reprimir a los disidentes y quitar las ganas de pensar de manera distinta a los jóvenes economistas que, terminado su doclorado en las mejores universidades, tienen la debilidad de tratar de analizar de manera original y crítica los problemas de nuestra sociedad y las soluciones que se proponen frente a ellos. Para los disidentes no hay dinero de investigación, no hay conferencias, ni consultorias generosas, ni la fama que dan los besi sellers... La represión intelectual que sufre la profesión, con su "pensamiento únicom, ha llevado a una falta de imaginación y creatividad a los jóvenes profesionales, algunos realmente inteligentes (porque la carrera de economía atrae a gente muy inteligente). El estilo intelectual de los economistas que quieren triunfar debe... ceñirse estriclamente a la definición más estrecha de to que es «la cconomía»... Lo que comienza como una añagaza metodológica acaba convirtiéndose en un convencimiento dogmático-religioso sobre la inmutabilidad del status quo. El miedo de economistas profesionales a salirse del mainstream y a no

52. Cfr. D. Schweickart, op. cit. pp. 399-4(19. 
encontrar, por tanto, trabajos bien remunerados (en bancos, consultorías, organismos y fundaciones internacionales, universidades y gobiernos), además de embotar la imaginación y reducir la creatividad, ha degenerado en incapacidad estructural, o bloqueo mental, para pensar soluciones reales luera del estrecho encasillado en que los inquisidores de la oferta y la demanda han metido a la argumentación económica. Y, naluralmente, allí no la encuentran"53.

El texto no tiene desperdicio, sobre todo porque viene firmado por un reconocido economisla, y me confirma en algo que barrunto hace liempo, gracias a una sugerencia de María López Vigil. El espiritu de Jesús debe estar suscitando en la humanidad y en la Iglesia vocaciones consagradas a la causa de las alternativas al modelo económico actual. De la misma manera que, en olras épocas, suscitó vocaciones de liberadores de csclavos, de educadores de pobres o de sanadores y cuidadores de enfermos. Seguramente se Irata de una vocación que necesita hombres y mujeres excelentemente preparados e institucionalizarse en organismos económicos diversos, pero a la que el Señor no le va exigir los Ires volos. Bastará con que sean obedientes a las necesidades de los pobres y se contenten con el sueldo, por ejemplo, de un profesional de ta educación.

\section{Conclusión: La enfermedad y el pecado ( $f f r$. Marcos 2, 1-12)54}

Seguramente nuestro mundo necesita de "un milagro" para desembarazarse de este tipo de globalización avasalladora de lo humano. Pero hoy como en los tiempos de Jesús, un milagro no es algo privado, sino con profundas repercusiones políticas y sociales. Las teorias económicas y socjales dominantes de los setenta desoyeron las voces que indicaban que el modelo de crecimiento económico y de consumo del Primer Mundo nos conducía a una crisis de recursos no renovables y de medio ambiente y a la inviabilidad del modelo de desarrollo postulado para ei Sur. El resuitado fue la crisis del petróleo, la agudización del deterioro ecológico y la declaración de una "década perdida" para América Latina.

Entonces, las autoridades económico-religiosas, al no poder echar la culpa de la situación a la irracionalidad de las propuesıas económicas, se vieron obligados a achacar las enfermedades de América Latina a sus propios comportamientos (de sus oligarquías, de los dicladores, de la apatía de las gentes, etc.), afirmando que eran sus “pecados” económicos los que tenían la culpa de todos sus males (leología de la retribución). En último término, la curación de las enfermedades producidas por el pecado estaba cn los "lemplos"

53. Prólogo, en D. Schweickart, op. cit, pp. 13-14.

54. Cfr. J. D. Crossan, Jesuis. Le vida de un campesino judio, Barcelona, 1994, p. 375. 
del Fondo Monetario Internacional y del Banco Mundial, lo cual supuso nuevas cargas en formas de ajustes estruclurales que nuevamente volvieron a pagar los más pobres. Así se cerraba el ciclo de victimización.

Así, pues, cuando Juan Pablo ll pide la reducción, si no la tolal condonación de la deuda exicrnass y un grupo de ciudadanos del mundo convocan a la globalización de la solidaridad, u hombres y mujeres de buena voluntad comprometen sus vidas en la resistencia al neoliberalismo y en la construcción parcial, fragmentaria de un modelo económico alternativo, implicitamentc están perdonando o declarando inexistentes los pecados económicos de América Latina y de los países empobrecidos (leología de la liberación). Su aclitud supone no ya un desafío al monopolio terapéutico de los economistas orodoxos, sino al monopolio religioso de los sacerdotes del "dios-mercado". Sus aclos, como los milagros de Jesús de Nazaret, son subversivos desde el punto de vista político. Pero en esta porfía, peligrosa por cierto, el reino del Dios de los pobres se abre camino en la historia.

55. Cfr. Terrio millenio adveniente 36: Instrumentum laboris 65 . 